Viso - Cadernos de estética aplicada Revista eletrônica de estética

ISSN 1981-4062

No 11, jan-jun/2012

http://www.revistaviso.com.br/

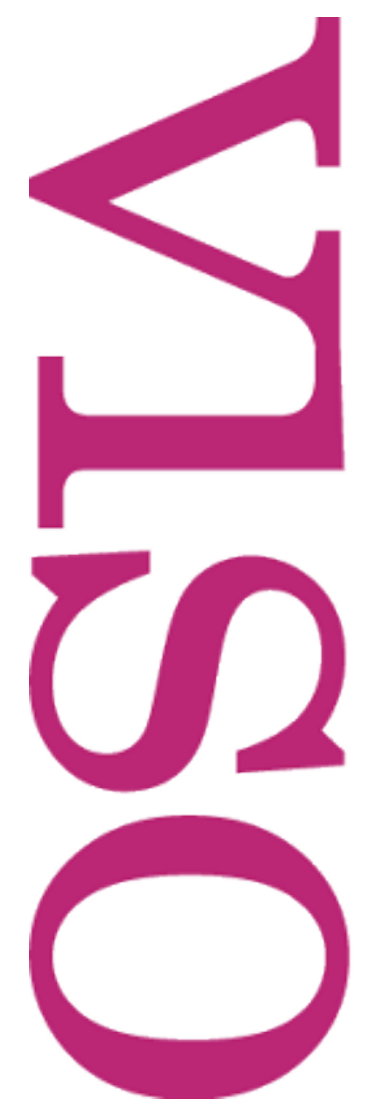

\title{
Narrar e saber: perguntas em torno da relação entre literatura e ciências \\ Cíntia Vieira da Silva
}




\section{RESUMO}

Narrar e saber: perguntas em torno da relação entre literatura e ciências A noção de paradigma indiciário, criada por Carlo Ginzburg, reúne espécies de discurso distintas em um gênero comum em função do papel da narrativa em tais discursos científicos e literários. Diante de tal perspectiva, surgem algumas indagações, que o presente texto procura equacionar. Se narrativas históricas, literárias, psicanalíticas, paleontológicas, e assim por diante, operam segundo o paradigma indiciário, não caberia insistir no que permite distinguir tais formas narrativas? O paradigma indiciário favorece o estabelecimento de relações não hierárquicas entre literatura e ciências? Por fim, será que tal paradigma seria enriquecido caso, às virtudes da caça, pudesse acrescentar aquelas da coleta?

Palavras-chave: ciências - indiciário - literatura - narrativa

\section{ABSTRACT}

To Narrate and to Know: Questions about the Relationship between

\section{Literature and Science}

The notion of evidentiary paradigm, created by Carlo Ginzburg, joins different kinds of discourse in a common genre due to the common role of narration in science and literature. From this point of view, there are some questions that this paper seeks to elaborate. If historical narratives, literary, psychoanalytic, paleontological, and so on, operate under the evidentiary paradigm, shouldn't we insist on distinguishing such narrative forms? Does the evidentiary paradigm favor the establishment of nonhierarchical relations between literature and science? Finally, could this paradigm be enriched if we could incorporate, to the virtues of the hunting, those of the collecting?

Keywords: science - evidentiary - literature - perspectives - differences 
SILVA, C. V. da "Narrar e saber: perguntas em torno da relação entre literatura e ciências". In: Viso: Cadernos de estética aplicada, v. VI, n. 11 (jan-jun/2012), pp. 211217.

DOI: $10.22409 / 1981-4062 / v 11 i / 134$

Aprovado: 18.06.2012. Publicado: 07.09.2012.

(C) 2012 Cíntia Vieira da Silva. Esse documento é distribuído nos termos da licença Creative Commons Atribuição-NãoComercial 4.0 Internacional (CC-BY-NC), que permite, exceto para fins comerciais, copiar e redistribuir o material em qualquer formato ou meio, bem como remixá-lo, transformá-lo ou criar a partir dele, desde que seja dado o devido crédito e indicada a licença sob a qual ele foi originalmente publicado.

Licença: http://creativecommons.org/licenses/by-nc/4.0/deed.pt_BR

Accepted: 18.06.2012. Published: 07.09.2012.

(C) 2012 Cíntia Vieira da Silva. This document is distributed under the terms of a Creative Commons Attribution-NonCommercial 4.0 International license (CC-BY-NC) which allows, except for commercial purposes, to copy and redistribute the material in any medium or format and to remix, transform, and build upon the material, provided the original work is properly cited and states its license.

License: http://creativecommons.org/licenses/by-nc/4.0/ 
Este texto é um comentário ao texto de Bernardo Barros Oliveira, publicado neste mesmo número da Revista Viso e retoma, em parte, os comentários que fiz durante o debate que se seguiu à apresentação realizada no Museu de Arte Contemporânea, em Niterói. Não me deterei na reconstrução dos argumentos nele apresentados, justamente porque o leitor pode fazê-lo por si mesmo. Meu breve comentário tem o intuito apenas de levantar algumas questões que a leitura do texto sugere, mas que não são diretamente abordadas nele. Com isto não quero fazer qualquer cobrança ao texto, que nada fica a dever. Se pensarmos nas restrições impostas pelas dimensões do texto (a versão lida no Encontro do GT de Estética tinha 8 páginas), teremos clareza da dificuldade que seria desenvolver o tema escolhido para além do que foi feito. Meu comentário, portanto, visa apontar algumas questões que o texto em questão, e os outros que ele convoca, nos dão a pensar, não indicar eventuais insuficiências ou coisa que o valha.

Uma primeira questão que me ocorreu concerne o que Bernardo Oliveira chama, com Carlo Ginzburg, de paradigma indiciário. Esta expressão recobre todo modo de pensar que se constrói por índices, ou signos, que são articulados em uma narrativa. Desse ponto de vista, pertenceriam ao paradigma indiciário tanto textos literários, quanto psicanalíticos, históricos, historiográficos e, de modo geral, muito do que se produz em humanidades poderia ser pensado à luz deste modelo. Pois bem, se todas essas produções colocam em jogo uma capacidade comum, a de narrar ou contar estórias ou histórias, deve haver algo nas maneiras singulares pelas quais cada uma delas se constitui como narrativa que permita distingui-las umas das outras. Quando se aproxima a narrativa literária da narrativa histórica, por exemplo, a construção de uma comunidade entre essas formas comumente vistas como distintas suscita questões a respeito do que as diferencia.

Mesmo que tal distinção não passe pela categoria da ficção, segundo uma repartição que distribuiria as narrativas entre ficcionais e não-ficcionais, ainda que algum teórico mais radical possa afirmar que tudo é ficção, uma vez que nenhuma forma do narrar dispõe mais da verdade como fundamento, ainda assim, e talvez com mais urgência, a questão das diferenças entre modos de narrar persistiria. Mesmo que se parta do pressuposto de que não há fatos independentes de interpretação, de que mesmo o registro da testemunha ocular de um determinado acontecimento se faz em função da perspectiva ocupada por aquele que vê (sem levar em conta tudo o que pode se passar entre o ver e o registrar ou contar); ainda assim parece-me que seria difícil considerar história e literatura como terrenos indistintos. Tal questão não é discutida nem mesmo no texto de Carlo Ginzburg, Sinais: raízes de uma paradigma indiciário, evocado por Bernardo Oliveira para iniciar suas reflexões em torno da narrativa literária. Talvez porque a tarefa de definir os termos do problema a que ela se reporta e de tentar respondê-lo seja árdua e só passível de se cumprir em grandes extensões, como atestam os três volumes de Paul Ricoeur em torno da narrativa, intitulados Tempo e narrativa. 
Voltando ao texto de Ginzburg, cumpre ressaltar que seu tema central, como seria de esperar pela trajetória intelectual do historiador, concerne mais ao que poderíamos chamar de uma epistemologia das ciências humanas do que à literatura, teoria literária, ou filosofia da arte. Parece-me que o interesse maior de Ginzburg neste texto é conferir estatuto de saber ou discurso portador de racionalidade aos vários tipos de produção veiculados nas humanidades, que escapam ao modelo das ciências modernas (especialmente da Física). Nesse sentido, a literatura ganharia destaque por ter sabido constituir um rico repertório de formas ligadas a este modelo de saber que o autor chama de indiciário. Segundo a leitura de Bernardo Oliveira, para Ginzburg, "a ficção cumpre o papel de fornecer um refúgio para um modo de conhecimento que visa atingir o particular, e não o universal". ${ }^{1}$ A frase me incomoda porque parece-me dar a entender que o mérito da literatura consistiria em fornecer material ou procedimentos para o desenvolvimento das ciências humanas, na medida em que se constituem como saberes interessados no particular. Isto me pareceria aceitável apenas com a condição de se deixar bem claro que tal mérito não se reduz a isso. Ainda assim, parece-me preferível afirmar a pertença de tais saberes, ao menos em certa medida, ao mundo da fiç̧ão (entendida como fabricação de narrativas), do que reivindicar o estatuto de saber ou conhecimento para a literatura. A razão de minha preferência é que, ao querer colocar a literatura como um tipo de saber, pode-se acabar por reafirmar a superioridade do conhecimento sobre a arte, o que não me parece ser de modo algum a intenção de Bernardo Oliveira.

Quanto a Ginzburg, seria abusivo, ou, pelo menos, exagerado, dizer que procura defender o conhecimento em detrimento da arte. $\mathrm{O}$ que se pode afirmar com segurança é que, no texto utilizado por Bernardo Oliveira, ele não se detém na análise de nenhum texto literário. No entanto, se sua preocupação mais importante é delinear um modelo para as ciências humanas que garanta seu interesse pelo particular, ao mesmo tempo em que assegure que tal tarefa possa ser cumprida segundo parâmetros definidos por uma racionalidade alternativa àquela centrada apenas na universalidade, não no irracionalismo, nem por isso deixa de ressaltar o papel da literatura na constituição desta racionalidade, ou, como prefiro, deste modo de pensar. Nesse sentido, Ginzburg evoca o texto de Thomas Huxley (1825-1895), ardoroso defensor do evolucionismo de Darwin, que nomeia o método "que reunia a história, a arqueologia, a geologia, a astronomia física e a paleontologia"2 com o título de um romance de Voltaire: Zadig.

Tal método envolveria a arte de reconstituir as causas, não verificáveis diretamente em função de sua antiguidade, a partir dos efeitos observáveis. Huxley, no título mesmo do texto citado por Ginzburg em nota, descreve tal método como profecia retrospectiva, considerando mais característico da profecia um certo tipo de olhar, e não uma determinada temporalidade (o futuro, no caso da adivinhação). Este olhar seria capaz de captar o que "escapa à esfera do conhecimento imediato" e se constituiria como "visão daquilo que é invisível ao sentido natural de quem vê". ${ }^{3}$ Neste ponto, surge outra inquietação. É que este olhar atento aos detalhes que escapam aos demais - olhar do 
profeta, do detetive, do narrador, do cientista das ciências do particular, do médico perito em diagnósticos ou semiótica médica - foi designado igualmente como olhar do caçador. Ainda que as imagens da caça como arte dos traços e dos rastros me pareça atraente, é irresistível perguntar: por que este olhar não poderia ser também o da coletora?

Ocorre a Ginzburg chamar o paradigma indiciário de venatório, ligando-o à caça como atividade exercida pelos grupos humanos desde tempos imemoriais. Para argumentar em favor da antiguidade do modo de pensar semiótico e fazer suas raízes remontarem muito além do século XIX, momento de emergência das ciências do particular e das formas literárias que estreitam os laços entre narração e investigação, Guinzburg afirma que "por milênios o homem foi caçador". ${ }^{4} \mathrm{O}$ curioso é que, provavelmente pelo mesmo número de milênios, mulheres e homens foram coletores. Por que, então, nada da atividade da coleta teria sido incorporado à capacidade de narrar? Por que a visão maximamente atenta aos detalhes requerida por esta atividade não é mencionada como elemento formador do saber indiciário? Ou a arte de encontrar a fruta mais doce, o mel, a larva, que, apesar de nos repugnar, tem nutrido a tantos humanos ao longo do tempo, não tem dignidade equivalente àquela de encontrar e matar o bisão, o javali e assim por diante? Caso nos lembrássemos das coletoras, teríamos outra história da narrativa, ou esta permaneceria inalterada?

Por último, a leitura do texto de Bernardo Oliveira faz pensar em um problema dos mais espinhosos no que toca as relações entre filosofia e artes. Se a filosofia não se coloca como superior às artes, como realização do espírito mais acabada do que elas, nem tampouco como inferior, como expressão empobrecida em comparação com elas, se a verticalidade é tida como superada, isto não nos garante os meios de efetuar a horizontalidade. Os que transitamos entre filosofia e artes corremos o risco de recair (ou subir) na verticalidade, sempre que descuidarmos do modo de nos posicionar diante das artes. Quando falamos, por exemplo, em aplicar um conceito filosófico à análise de uma obra de arte, não estaríamos sobrepondo o conceito à obra? E não padeceríamos do mesmo mal ao elegermos uma obra como exemplo de um conceito ou conjunto de conceitos? O texto de Bernardo Oliveira se desenrola neste fio de navalha e corre o risco mencionado de colocar o romance que comenta apenas a serviço de um diagnóstico conceitual prévio à leitura dele. A primeira menção a Magnólia, romance de Bernardo Carvalho, é feita em termos que aumentam o risco, na medida em que o romance aparece como "oportunidade [...] de discutir o nosso ponto central" ${ }^{\text {, }}$ que, se bem entendi, seriam as transformações recentes sofridas pela narrativa, que a levam a se configurar como meta-narrativa, ou narrativa consciente de si, que conta sua própria história. A questão central do texto parece ser a de como tem sido possível narrar em tempos de crise da narrativa.

Seguindo a sugestão que presidiu a concepção do Encontro do GT de tratar de temas referentes ao Brasil, o texto debruçou-se sobre um romance brasileiro recente. É difícil, entretanto, desfazer a impressão de que a referência ao romance serve para exemplificar 
a teoria da narrativa desenvolvida nas páginas anteriores, de que o romance em questão não interpelou o autor do texto, não se colocou como questão para ele em sua singularidade, nem suscitou efetivamente sua vontade de intérprete ou crítico, mas funcionou como recurso para dar a ver um conceito do qual ele seria um caso. O texto retoma aspectos da trama do romance, reconta sua estória, alude a alguns de seus detalhes. Contudo, parece que isto é feito na medida em que os detalhes corroboram o conceito de narrativa anteriormente elaborado no texto. Tal impressão sugere que se coloque em dúvida a escolha do romance a ser comentado. Talvez um romance recente, com pouca ou nenhuma fortuna crítica, de impacto mitigado na tradição literária brasileira possa facilmente se prestar a um papel subordinado em texto filosófico. E provavelmente a estória seria outra, caso o romance escolhido tivesse sido um daqueles consensualmente tidos como grandes em nossa literatura. Ou algum outro que, mesmo recente, colocasse mais pulgas atrás da orelha do filósofo.

\section{* Cíntia Vieira da Silva é professora adjunta do Departamento de Filosofia da UFOP.}

1OLIVEIRA, B. "Do tradicional ao indiciário, e depois. Uma narrativa contemporânea brasileira." In: Viso: Cadernos de estética aplicada. Rio de Janeiro, n. 11.

${ }^{2}$ GINZBURG, C. Mitos, emblemas, sinais. Sinais; raízes de uma paradigma indiciário. Tradução de Federico Carotti. São Paulo: Companhia das Letras, 1989, p. 169.

${ }^{3} \mathrm{HUXLEY}, \mathrm{T}$. Science and culture. On the method of Zadig: retrospective prophecy as a function of science. Londres, 1881, p. 132. Apud: GINZBURG, C. Op. cit., p. 271, nota 94.

${ }^{4}$ GINZBURG, C. Op. cit., p. 151.

${ }^{5}$ OLIVEIRA, B. Op. cit., p. 5. 